Volume 3 • Nomor 2 • Februari 2020

Pege $($ Hal. $): 48-53$

(C) Universitas Pamulang

JL.Surya Kencana No.1 Pamulang, Tangerang Selatan - Banten

website. :

Telp. (021) 7412566, Fax (021) 7412491

http://www.openjournal.unpam.ac.id/index.php/JPK

Email : jurnalmarketing.unpam@gmail.com

\title{
Upaya Meningkatan Publisitas Melalui Model Integrated Marketing Comunication Pada Sebuah Rumah Sakit Swasta di Tangerang Selatan
}

\author{
Surti Wardani ${ }^{1}$, Arif Siaha Widodo ${ }^{2}$ \\ Universitas Pamulang \\ Email : dosen01707@unpam.ac.id
}

\begin{abstract}
There are two Hermina Hospitals in South Tangerang. Although they have implemented a marketing communication strategy but not the Integrated Marketing Communication (IMC) model. This research aims to describe the marketing communication strategy used by the Hermina Hospital in South Tengerang. The focus of this research is on how marketing communication is available at the two Hermina Hospitals in making marketing communication models so that the services delivered are integrated. The method of this research is descriptive qualitative by observing the public. Data obtained by interviewing informants. The selection of research informants was by using purposive sampling method to obtain information about the characteristics of the hospital service user community. The results of the study produced an integrated marketing communication model can be used as a basis for making policies in increasing hospital publicity.
\end{abstract}

Keywords: Strategy, Model, Integrated Marketing Communication (IMC).

\section{A. PENDAHULUAN}

Rumah Sakit adalah merupakan sebuah perusahaan yang pada mulanya bergerak sebagai perusahaan nirlaba. Sebuah Rumah Sakit sebagai sarana pelayanan kesehatan masyarakat yang di dalamnya mengedepankan nilai norma moral, maupun nilai tatanan etika yang keberadaanya diselenggarakan oleh negara ataupun swasta. Di dalam perkembanganya hingga saat ini Rumah Sakit tidak hanya bergerak sebagai perusahaan nonprofit akan tetapi berubah menjadi perusahaan profit oriented. Akan tetapi walaupun Rumah Sakit berorientasi kepada profit, sebuah Rumah Sakit tetap harus berpegang pada norma moral dan norma etika di Indonesia.

Setiap perusahaan dalam menjalankan bisnisnya semestinya mengetahui siapa target pasarnya dan bagaimana berkomunikasi antara perusahaan kepada konsumen yang menjadi target pasarnya. Apabila terjadi kesalahan dalam menentukan strateginya, maka target yang dituju tidak akan tercapai. Sebagaimana dikemukakan oleh Hermawan Kertajaya yang dikutip oleh Buhori Alma ( 2018,3 ) pemasaran adalah "Sebuah disiplin strategis yang mengarah pada proses penciptaan, penawaran dan perubahan values dari inisiator kepada stakeholder ". Apabila strategi yang digunakan disusun dengan terencana ,yaitu dalam menerapkan strategi komunikasi pemasaran seperti yang telah diterapkan oleh perusahaan, seperti periklanan, personal selling, sales promotion, public relation, dan direct marketing, 
maka bisa dipastikan akan membawa dampak positif dalam meningkatkan publisitas perusahaan.

Berdasarkan hasil penelitian yang telah dilakukan kepada dua Rumah Sakit Hermina di Tangerang Selatan, yang menjadi sasaran penelitian kedua Rumah Sakit Hermina tersebut telah melakukan lima komunikasi pemasaran yaitu; Periklanan, personal selling, sales promotion, public relation dan direct marketing. Tetapi dari forum group discusion

FGD ) dengan pihak manajemen Rumah Sakit Hermina menunjukan strategi pemasaran yang dilakukan hanya pada kebutuhan yang sifatnya sesaat. Padahal untuk melakukan proses kmunikasi antara perusahaan kepada konsumen harus dilakukan secara terus menerus dan berkesinambungan. Tujuannya adalah agar konsumen atau pelanggan dapat mengenali lebih dalam tentang Rumah Sakit tersebut, dalam hal ini Rumah Sakit Hermina di Tangerang Selatan.

Dalam membangun citra merek perusahaan agar mudah untuk dikenal di masyarakat umum, tidak bisa dijalankan dalam waktu yang pendek, namun diperlukan strategi khusus dan terus menerus serta berkesinambungan. Dua Rumah Sakit Hermina di Tangerang Selatan ( Rumah Sakit Hermina Ciputat, Rumah Sakit Hermina Serpong ) dipilih sebagai obyek penelitian serta makalah ini akan menganalisa temuan penelitian terkait strategi pemasaran khususnya Integrated Marketing Communication ( IMC ) yang diterapkan perusahaan.

\section{B. KAJIAN LITERATUR}

\section{Komunikasi :}

Asal kata komunikasi berasal dari kata Communication (dari bahasa latin) yang berarti memberitahukan, dengan memberikan bagian (dalam sesuatu), pertukaran di mana seorang pembicara akan menginginkan pertimbangan dan tanggapan dari pendengarnya. Komunikasi jika dilihat dari kata sifatnya adalah Communis yang artinya bersifat umum atau bersama - sama. Sedangkan kata kerjanya berasal dari kata Communicare yang berarti berbicara, melakukan perundingan ataupun melakukan musyawarah (Daryanto, $2010: 63$ ). Dengan demikian bisa di ambil kesimpulan bahwa Komunikasi disebut juga sebuah kesamaan antara pengirim dengan penerima ( Shimp, 2003:163 ). Atau arti dari definisi ini adalah di perlukan kesamaan dalam berpikir yang di kembangkan antara pihak pengirim dan pihak penerima apabila terjadi komunikasi. Dalam kesamaan ini diperlukan untuk saling berbagi ( sharing ), di antara pengirim ( Pengiklan ) dengan pihak penerima iklan ( Konsumen ).

\section{Strategi :}

Strategi adalah merupakan kerangka berfikir ( Strategic Thinking ), Apabila tujuan komunikasi sebatas company ( berfikir sekala kecil/mikro ) maka hasilnya hanya akan memperoleh hal yang sifatnya jangka pendek. Bahwa yang di maksud dengan strategi di sini adalah kemampuan memimpin dalam mengembangkan sebuah visi yang akan mengarahkan perusahaan dalam hal ini Rumah sakit Hermina, untuk mengembangkan model bisnis yang akan menjadikan kerangka acuan perusahaan di dalam menggunakan sumber daya yang di miliki perusahaan dalam hal ini Rumah Sakit Hermina, Visi dari sebuah perusahaan di ibaratkan sebagai sebuah perahu besar yang berjalan kearah yang benar. Di dalam mengarahkan perusahaan perlu visi yang mampu mengarahkan perusahaan dalam jangka panjang. 


\section{Komunikasi Pemasaran :}

Komunikasi pemasaran bertujuan untuk mencapa tujuan perusahaan ( Shimp.2003:106 ) menyebutkan tujuan tersebut meliputi : Membangkitan sebuah keinginan terhadap suatu kategori produk, membuat kesadaran akan merek, dan dapat mendorong citra positif akan sebuah merk, serta menfasilitasi pembelian. Di dalam proses penerimaan sebuah produk oleh konsumen akan melalui proses mendengar informasi produk, dan pada akhirnya mengambil keputusan untuk mengkonsumsi produk tertentu. Informasi yang di sampaikan dengan baik akan menjadikan konsumen untuk berusaha mencari informasi mengenai suatu produk yang kurang atau belum di ketahuinya.

\section{Integration Marketing Comunication ( IMC ) :}

Menurut Kotler (2004:220 ) Integration Marketing Communication ( IMC ) adalah merupakan sebuah konsep yang menjadi landasan dalam upaya perusahaan mengintegrasikan strategi di dalam memberikan pesan yang jelas, selalu konsisten, dan lebih persuasif mengenai perusahaan dan produknya. Menurut Gronroos (2000:221) menyebutkan bahwa Integrated Marketing Communication (IMC) adalah merupakan strategi yang yang mengintegrasikan model media marketing tradisional, direct marketing, public relation serta jenis media pemasaran lainya, dan aspek komunikasi di dalam penyampaian serta konsumsi barang dan jasa dan pelayanan terhadap pelanggan.

Dari penjelasan di atas maka dapat diambil kesimpulan bahwa Integrated Marketing Communication ( IMC ) adalah sebuah strategi mengintegrasikan secara baik dan tidak hanya terfokus kepada pelanggan saja, tetapi perusahaan diharuskan mendengar dari semua pihak (stakeholder) termasuk di dalamnya konsumen yang berhubungan langsung dengan public, yang mampu menyebarkan komunikasi mulai dari produk yang dikonsumsi, logo atau lambang perusahaan, testimoni setelah menggunakan produk, iklan, layanan kepada pelanggan, serta berita di sebuah media massa, sampai pada rumors yang dapat menyebar dengan cepat secara berantai.

Dalam penelitian ini, komunikasi pemasaran yang menjadi fokus penelitian adalah metode periklanan, metode personal selling, metode sales promotion, metode public relation, serta metode direct marketing. Terdapat lima komponen yang diterapkan Rumah Sakit Hermina secara terintegrasi.

\section{METODE PENELITIAN}

Metode yang di gunakan dalam penelitian ini adalah metode penelitian deskriptif kualitatif dengan menggunakan sebuah studi kasus. Penelitian ini berlokasi di Rumah Sakit Hermina Ciputat, dan Rumah Sakit Hermina Serpong. Data primer berasal dari para informan yang ada di kedua Rumah sakit tersebut. Dan data sekunder dalam penelitian ini di perlukan sebagai salah satu data yang mendukung dalam penelitian ini.

Dalam mengumpulkan data, peneliti menggunakan beberapa metode diantaranya metode observasi, metode wawancara, dan Focus Group Discusion (FGD) serta dokumentasi. Dalam menganalisis data menggunakan metode analisa interaktif. Dalam buku Sutopo ( 2002:94 ) Miles dan dan Huberman menjelaskan bahwa dalam olah data dengan menggunakan model interkatif ini terbagi menjadi beberapa komponen yaitu : komponen reduksi data, komponen sajian data, serta pengambilan kesimpulan dengan verifikasi yang sudah di buat sebelumnya. 


\section{HASIL DAN PEMBAHASAN}

\section{Rumah Sakit Hermina Serpong}

Rumah Sakit Hermina Serpong memilih metode komunikasi pemasaranya dengan metode periklanan, personal selling, sales promotion, public relation dan direct marketing secara keseluruhan. Berdasarkan interview dengan pihak manajemen Rumah Sakit yang merupakan informan internal Rumah Sakit Hermina Serpong, di peroleh informasi bahwa pihak Rumah Sakit Hermina Serpong telah melakukan lima jenis komunikasi pemasaran sebagai upaya dalam meningkatkan publisitas Rumah Sakit.

Dalam Metode periklanan strategi yang dipilih Rumah Sakit dengan menggunakan cara tidak vulgar. Dikarenakan ada aturan yang mengikat kepada sebuah Rumah Sakit apabila menggunakan metode periklanan. Sehingga metode periklanan biasanya digunakan dengan cara menjadi sponsor pada acara - acara terterntu misalnya menjadi sponsor pada acara seminar atau kegiatan tertentu lainya dengan cara memasang spanduk pada saat kegiatan berlangsung.

Sementara dalam metode Personal Selling yang dilakukan pihak Rumah Sakit Hermina Serpong yaitu dengan cara melakukan kerjasama dengan berbagai perusahaan. Misalnya menggandeng perusahaan asuransi untuk mengasuransikan karyawannya dengan bekerjasama dengan pihak Rumah Sakit. Selain itu menjalin kerjasama dengan instansi yang lebih kecil lagi misalnya klinik bersalin. Pada kasus apabila terdapat pasien yang memerlukan dirujuk ke Rumah Sakit yang lebih besar untuk merujuk ke Rumah Sakit Hermina.

Dalam metode Sales Promotion yang dilakukan pihak Rumah Sakit yaitu dengan memberikan discount kepada anggota keluarga karyawan Rumah Sakit yang melakukan pengobatan rawat inap. Selain itu juga dengan memberikan pengurangan biaya untuk pasien dari keluarga kategori kurang mampu. Memberikan paket promo seperti cek darah, paket imunisasi kanker serviks dan lainnya.

Public relation yang di lakukan oleh Rumah Sakit Hermina yaitu dengan cara mengadakan pengobatan gratis seperti operasi katarak gratis, operasi bibir sumbing gratis serta khitanan massal bagi keluarga kurang mampu yang berada di wilayah Tangerang Selatan.

Direct Marketing yang dilakukan oleh rumah sakit di antaranya adalah dengan membuat website yang bisa dilihat secara umum.

Berdasarkan wawancara dengan pihak luar Rumah Sakit ( pasien, keluarga pasien, dan masyarakat sekitarnya ) bahwa apa yang telah dilakukan oleh Rumah Sakit Hermina Serpong tidak semuanya diketahui oleh pihak luar, iklan Rumah Sakit misalnya spanduk hanya diketahui oleh masyarakat yang lewat di sekitar spanduk yang di pasang oleh pihak Rumah Sakit, Personal Selling yang di lakukan pihak Rumah Sakit tidak tersampaikan dengan maksimal kepada pasien dan masyarakat pada umumnya.

Pasien yang melakukan pengobatan, pada umumnya belum mengetahui tentang adanya kerjasama yang telah dilakukan dengan perusahaan tertentu yang dijalinnya, sehingga pasien berobat dengan menggunakan biaya sendiri atau dengan jaminan kesehatan lainya. Akan tetapi ada pula yang memperoleh informasi dari tetangga atau saudara yang pernah berobat ke Rumah Sakit Hermina.

Sales Promotion juga belum semuanya di pahami oleh masyarakat, ada sebagian pasien yang menggunakan fasilitas keringanan biaya karena dari masyarakat miskin, akan tetapi masih ada pula masyarakat yang merasa keberatan dengan biaya berobat yang harus di tanggungnya dan tetap tidak mendapatkan pengurangan biaya pengobatannya. 
Metode Direct Marketing berupa website ternyata pasien serta masyarakat pada umumnya juga belum semua mengakses website tersebut, namun ada beberapa pasien yang mengaku pernah membacanya akan tetapi hanya sekilas saja.

Berdasarkan data tersebut dapat di analisis bahwa pihak manajemen Rumah Sakit Hermina Serpong perlu mengetahui kultur masyarakat sekitar, terlebih kepada pengguna layanan Rumah Sakit, dengan demikian dalam menentukan komunikasi apa yang akan dipilih, pesan yang ingin disampaikan bisa diterima kepada sasarannya. Oleh karena itu di perlukan suvei terlebih dahulu yang dilakukan oleh pihak Rumah Sakit baru kemudian membuat perencanaan komunikasi terpadunya atau lebih dikenal dengan istilah Integrated Marketing Communication ( IMC).

\section{Rumah Sakit Hermina Ciputat}

Hasil penelitian pada Rumah Sakit Hermina Ciputat hasilnya tidak jauh berbeda dengan hasil penelitian pada Rumah Sakit Hermina Serpong. Dari pihak internal Rumah Sakit ketika diwawancarai oleh peneliti, menyebutkan bahwa Rumah Sakit Hermina Ciputat telah melakukan beberapa jenis metode komunikasi pemasaran ( metode periklanan, metode personal selling, metode sales promotion,metode public relation dan metode direct marketing). Akan tetapi pada saat peneliti melakukan pengecekan kepada masyarakat di daerah Ciputat, khususnya kepada para pasien yang menggunakan jasa pelayanan Rumah Sakit Hermina Ciputat, belum sepenuhnya komunikasi pemasaran yang dipilih Rumah Sakit bisa diketahui dan dipahami oleh pasien. Pihak Rumah Sakit Hermina Ciputat mengatakan bahwa metode periklanan yang pernah dilakukan adalah berupa sponsorship dengan memasang spanduk pada saat kegiatan hari kesehatan nasional maupun pada acara - acara tertentu di wilayah Ciputat dan sekitarnya.

Selain itu juga Rumah Sakit telah menyediakan leaflet yang isinya mengenai Rumah sakit Hermina Ciputat.

Personal Selling juga telah di lakukan dengan cara mendatangi klinik bersalin yang ada di sekitar Ciputat untuk memberikan rujukan kepada pasien yang akan melahirkan dan memerlukan penanganan dokter spesialis kandungan di mana di klinik tersebut belum menyediakan pelayanan dokter spesialis kandungan.

Program Sales Promotion dilakukan dengan cara memberikan keringanan biaya pengobatan kepada masyarakat kurang mampu yang melakukan pengobatanya ke Rumah Sakit Hermina Ciputat. Selain itu juga memberikan discount kepada anggota keluarga karyawan Rumah Sakit Hermina Ciputat.

Public Relation dilakukan dengan cara melakukan kegiatan seminar tentang kesehatan tertentu yang diadakan oleh pihak Rumah Sakit dengan peserta masyarkat umum di seputar Ciputat dan peserta seminar tidak dipungut biaya untuk keikutsertaanya dalam kegiatan seminar. Sementara kegiatan direct marketing Rumah Sakit juga telah mempunyai website di mana website tersebut berisi semua informasi mengenai Rumah Sakit Hermina Ciputat yang dapat di akses secara umum.

Namun demikian semua informasi yang disampaikan kepada masyarakat belum sepenuhnya diketahui dan dalam proses komunikasi pemasaranya belum sepenuhnya terintegrasi dengan baik. Semua kegiatan komunikasi pemasaran yang dilakukan berjalan sendiri sendiri, ketika peneliti melakukan pengecekan kepada masyarakat ternyata sebagian masyarakat di sekitar ciputat atau pasien sebagian besar tidak mengetahui bahwa rumah sakit Hermina Ciputat telah melakukan kegiatan sponsorship dalam kegiatan tertentu di 
sekitar Ciputat. Akan tetapi ada sebagian masyarakat yang pernah membaca leaflet tentang Rumah Sakit Hermina Ciputat.

\section{E. KESIMPULAN}

Berdasarkan penelitian yang sudah dilakukan oleh peneliti, maka kesimpulan yang bisa di ambil sebagai berikut :

1. Kedua rumah Sakit baik Rumash Sakit Hermina Serpong maupun Rumah Sakit Hermina Ciputat telah menggunakan 5 komunikasi pemasaran yaitu, periklanan, sales promotion, personal selling, public relationship, direct marketing .

2. Metode Komunikasi pemasaran yang telah dilakukan belum dilaksanakan secara konsisten sehingga pengguna jasa layanan Rumah Sakit belum mengetahui seluruhnya komunikasi pemasaran yang dilakukan Rumah Sakit.

3. Integrated Marketing Comunication ( IMC ) belum dijalankan secara optimal oleh Rumah, komunikasi pemasaran berjalan sendiri -sendiri.

4. Dihasilkan model pengembangan strategi komunikasi pemasaran yang bisa dijadikan model oleh Rumah Sakit dalam menentukan metode komunikasi pemasaran yang tepat untuk dipilih.

\section{DAFTAR PUSTAKA}

Daryanto.( 2010 ) Ilmu Komunikasi. Bandung : PT. Sarana Tutorial Nurani Sejahtera

Gronroos, C. (2000). Service Management and Marketing, A Marketing Relationship Management Approach. Second Edition. West Sussex: Chicheste.

Iskandar. (2009), Metode Penelitian Kualitatif. Jakarta: Gaung Persanda.Sholihin, Ismail. (2012). Manajemen Strategik. Jakarta: Penerbit Erlangga.

Perhimpunan Rumah Sakit Seluruh Indonesia (PERSI). (2011). Pedoman Etika Promosi Rumah Sakit, Jakarta.

Philip Kotler. (2004). Manajemen Pemasaran. Jakarta: Penerbit Erlangga.

Terence. A. Shimp. (2003). Periklanan Promosi Aspek Tambahan Komunikasi Pemasaran Terpadu. Jakarta: Erlangga.

Sutisna. (2002). Perilaku Konsumen \& Komunikasi Pemasaran. Bandung: PT. Remaja Rosdakarya.

Sotopo, HB. (2002). Metode Penelitian Kualitatif, Surakarta: UNS Press.

William R. Gombeski, Jr et al, (2007). Effectively Executing a Comprehenshive Marketing Communication Strategy. Journal of Health Marketing Quarterly (The Howarth Press). Vol 24 No. 3/4 pp 97-115.

Watono, A.Adji dan Maya C.Watono. (2011). IMC Integrated Marketing Communication that Sells. Jakarta: Penerbit PT Gramedia Pustaka Utama.

Yahya, Arief. (2012). Great Spirit Grand Strategy. Jakarta: PT Gramedia Pustaka Utama. 